\title{
Protocol
}

\section{Mouse Mutagenesis Using N-Ethyl-N-Nitrosourea (ENU)}

\author{
Andrew P. Salinger and Monica J. Justice ${ }^{1}$ \\ Department of Molecular and Human Genetics, Baylor College of Medicine, Houston, TX 77030, USA
}

\section{INTRODUCTION}

This protocol describes chemical mutagenesis of male mice using $N$-ethyl- $N$-nitrosourea (ENU), which is the most efficient method for obtaining mouse mutations in phenotype-driven screens. A fractionated dose of ENU, an alkylating agent, can produce a mutation rate as high as $1.5 \times 10^{-3}$ in male mouse spermatogonial stem cells. Treatment with ENU produces point mutations that provide a unique mutant resource: They reflect the consequences of single gene changes independent of position effects, provide a fine structure dissection of protein function, display a range of mutant effects from complete or partial loss of function to exaggerated function, and discover gene functions in an unbiased manner. After treatment with ENU, mice are mated in genetic screens designed to uncover mutations of interest. Screens for dominant, recessive, and modifying mutations can be performed.

\section{MATERIALS}

CAUTIONS AND RECIPES: Please see Appendices for appropriate handling of materials marked with $\langle$ ! $>$, and recipes for reagents marked with $<\mathbf{R}>$.

\section{Reagents}

Ethanol (95\%)

Inactivating solution

ENU has a very short half-life under alkaline conditions. Prepare one of the following solutions for ENU inactivation:

$<!>0.1 \mathrm{M} \mathrm{KOH}\left(5.6 \mathrm{~g} \mathrm{KOH}\right.$ pellets dissolved in $1000 \mathrm{~mL} \mathrm{H} \mathrm{H}_{2}$ )

$<\mathbf{R}>$ Alkaline sodium thiosulfate

Mice (males of appropriate strain; 8-12 wk old), for injection

$<$ ! > N-ethyl-N-nitrosourea (ENU) (1-g ISOPAC containers; Sigma N3385)

The labeling of $1 \mathrm{~g}$ of ENU per container is only approximate. The actual amount per container ranges from about $0.7 \mathrm{~g}$ to $1.2 \mathrm{~g}$ (see Steps 3-4).

$<\mathbf{R}>$ Phosphate/citrate buffer

\section{Equipment}

Bags (plastic)

Chemical fume hood

Cuvettes (plastic disposable)

Foil

Glass waste container 
Hazardous waste container (chemical)

Needle (18-gauge)

Paper for changing bedding (optional; see Step 11)

Protective clothing for handling ENU (plastic gloves, lab coats, and masks)

Scale for weighing mice

Spectrophotometer

Syringes

- plastic (10- and 30-cc)

- tuberculin (1-cc, with 26-gauge, 3/8-in needles)

\section{METHOD}

\section{Preparation of ENU Solution}

ENU is very sensitive to light, humidity, and $\mathrm{pH}$. Dilute a new container of ENU prior to each weekly injection and protect from light using a foil wrap. Inject mice (Step 7) within $3 \mathrm{~h}$ of diluting the ENU.

\section{Dissolving and Diluting ENU}

1. In an efficient chemical fume hood, dissolve the ENU by injecting $10 \mathrm{~mL}$ of $95 \%$ ethanol into the ISOPAC container of ENU. Gently agitate the suspension until the ENU goes into solution. Use the warmth from your hands to warm the containment vessel.

Handlers should wear plastic gloves, lab coats, and masks.

The solution should be clear and yellow in color when the ENU is completely dissolved. This will take up to $10 \mathrm{~min}$. See Troubleshooting.

2. Dilute the ENU using one of the following methods:

i. For a standard solution, inject $90 \mathrm{~mL}$ of phosphate/citrate buffer into the ISOPAC container vented with an 18-gauge needle. Mix thoroughly.

ii. To prepare a more dilute solution, remove $5 \mathrm{~mL}$ of ENU from the ISOPAC container prior to dilution and place it directly into $50 \mathrm{~mL}$ of inactivating solution (e.g., $0.1 \mathrm{M} \mathrm{KOH}$ or alkaline sodium thiosulfate). Discard after a minimum of $2 \mathrm{~h}$. Inject $95 \mathrm{~mL}$ of phosphate/citrate buffer into the ISOPAC container.

A more dilute solution is preferable for injection of small quantities of ENU per mouse.

\section{Determining Concentration by Spectrophotometry}

Because the amount of ENU per container varies, the concentration of each prepared ENU solution must be determined empirically. Measurement of concentration also controls for dilution errors.

3. Transfer $400 \mu \mathrm{L}$ of the suspended ENU to a disposable plastic cuvette and bring the volume to $2000 \mu \mathrm{L}$ with phosphate/citrate buffer (a 1:5 dilution). Prepare a 1:50 dilution of 95\% ethanol in phosphate/citrate buffer (also in a plastic disposable cuvette) to use as a blank. Determine the $\mathrm{OD}_{398 \mathrm{~nm}}$ of the ENU relative to the blank.

The OD at this wavelength will vary depending upon the concentration of the ENU solution.

4. Calculate the concentration of the ENU in solution based upon the observation that a $1 \mathrm{mg} / \mathrm{mL}$ solution gives an $\mathrm{OD}_{398 \mathrm{~nm}}$ of 0.72 .

To ensure that the spectrophotometer is working appropriately, perform a wavelength scan from 350 to $450 \mathrm{~nm}$. This scan should give a peak reading at $O D_{398}$. We recommend performing the scan at least once per year.

\section{Injection of Male Mice with ENU}

Injections may be a single dose of ENU or a fractionated dose. Determine which is appropriate for your experiment and strain of mice. Fractionated doses are administered weekly at approximately the same time each week.

Males should be fully sexually mature ( $8 \mathrm{wk}$ ) prior to injections. If a fractionated dose is used, the experiment will take 3 wk; thus, it is important to begin the experiment with 8- to 9-wk-old males (not older mice). 
5. Determine the live weight of each mouse prior to each injection and record. Mark each animal to distinguish it on subsequent days.

6. Calculate the volume of ENU for injection depending on the desired dose. For $100 \mathrm{mg} \mathrm{ENU} / \mathrm{kg}$ mouse body weight, the calculation is as follows:

$$
\mathrm{X}(\mathrm{mL} / \mathrm{g})=\frac{0.100 \mathrm{mg} / \mathrm{g} \text { mouse body weight }}{\mathrm{OD}_{398} \times 5}
$$

where 0.72 is $\mathrm{OD}_{398 \mathrm{~nm}}$ at $1 \mathrm{mg} / \mathrm{mL}$ and 5 is the dilution factor (see Steps 3-4).

Volume of ENU to inject $(\mathrm{mL})=$ mouse weight $(\mathrm{g}) \times \mathrm{X}$.

The concentration of the ENU solution should be such that $<1 \mathrm{~mL}$ is injected into each animal.

Various inbred strains of mice react differently to a given dose of ENU. Likewise, different doses of ENU give different mutation rates. To produce the highest mutation rate, an appropriate amount for C57BL/6J mice is three weekly doses of $100 \mathrm{mg} / \mathrm{kg}$ body weight. An effective single dose is $250 \mathrm{mg} / \mathrm{kg}$. Protocols for optimizing doses for different inbred strains are referenced in the Discussion.

7. In an efficient chemical fume hood, administer the appropriate amount of ENU intraperitoneally to each mouse.

Animals may appear wobbly and lethargic for $\sim 30$ min after injections because of the alcohol. It should take $\sim 1 \mathrm{~h}$ to inject 30 mice.

\section{Inactivation and Disposal of ENU}

8. Clean all spills and soak all equipment (beakers, vials, etc.) and gloves coming into contact with ENU with inactivating solution. Pull up inactivating solution into all needles that have been in contact with ENU. Put treated items in a plastic bag and discard in waste. Inactivate any remaining ENU solution and discard appropriately.

9. Inject at least $50 \mathrm{~mL}$ of inactivating solution into the remaining ENU in the ISOPAC container. Leave in a chemical fume hood, exposed to light, for at least $24 \mathrm{~h}$.

10. Remove the seal from the ISOPAC container and discard the inactivated ENU into a chemical hazardous waste container. Record appropriately. Rinse the ISOPAC container with $\mathrm{H}_{2} \mathrm{O}$, and discard the contents into a chemical hazardous waste container. Discard the emptied ISOPAC container in glass waste.

11. Keep mice in an efficient chemical fume hood for at least $24 \mathrm{~h}$ after injections, or change bedding at least $24 \mathrm{~h}$ after injections into a plastic bag containing paper saturated with inactivating solution. (This usually requires marking the pens containing treated animals.)

\section{Mating Males to Recover Mutations}

12. After injection, males go through a period of infertility that lasts $\sim 10-12$ wk. Set up males in cages with females 8-10 wk after the last injection to assess recovery of fertility.

See Troubleshooting.

13. Select an appropriate breeding scheme, according to the mutation of interest.

The breeding scheme will depend on the type of mutation being studied, i.e., dominant, recessive, or modifying (see Discussion). Plan to recover about 50 gametes per male for dominant or modifying mutations, and about 30 gametes per male for a recessive scheme.

14. Use rotation matings (see Fig. 1) to mate the males according to the breeding scheme chosen in Step 13. Mate the males to a new female (or two new females, depending upon animal protocol) each week for 6-7 wk, until the appropriate number of gametes has been obtained. Set up each new cage as it is needed each week.

The females will be pregnant for 3 wk and nursing their young for an additional 3 wk. After weaning, the females can rest for $1 \mathrm{wk}$ and then be recycled through another male until they lose reproductive capacity.

See Troubleshooting. 


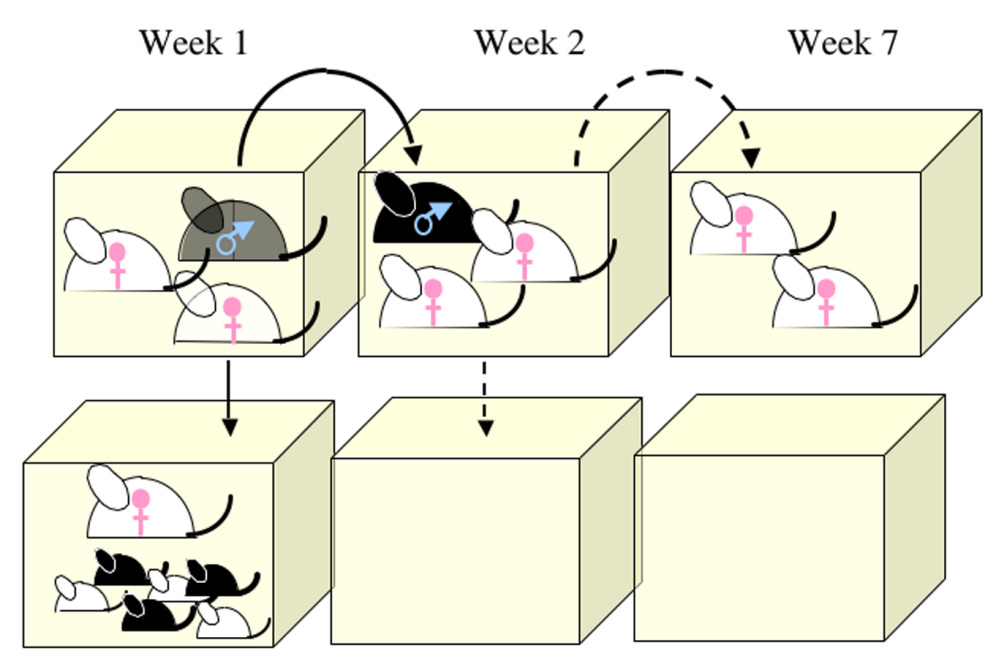

FIGURE 1. A schematic diagram showing rotation matings. Obtaining the appropriate number of gametes from each treated male is important for mutagenesis. To obtain enough gametes before ENU-treated males succumb to illness (in particular, the commonly used $\mathrm{C} 57 \mathrm{BL} / 6 \mathrm{~J}$ strain is susceptible to the development of T-cell lymphoma), rotation matings are advised. Place each male into a new cage with one or two females each week for 6 - wk, depending upon how many gametes are needed from each male. If two females are used, a pregnant female can be placed into a separate cage for bearing her litter, if required by the institutional animal protocol. The rotation breeding strategy also improves efficiency of weaning and mutation recovery. Females are shown in white; males are shown in black.

\section{TROUBLESHOOTING}

Problem: The ENU does not dissolve.

[Step 1]

Solution: Use $95 \%$ ethanol as the solvent, and be sure that the ENU is completely dissolved in ethanol before adding the phosphate/citrate buffer.

Problem: Males do not recover fertility.

[Step 12]

Solution: Consider the following:

- It is normal for some males to never recover fertility. For example, in the C57BL/6] strain, using a $3 \times 100 \mathrm{mg} / \mathrm{kg}$ dose, about one-fourth to one-half of the males do not recover fertility. Allow for this loss of males by injecting an appropriate (greater) number of males.

- If no males recover fertility, the dose of ENU may be too high.

- It may be useful to ask the following questions: What strain of mouse was used? Was the dose administered appropriate for that strain? Was the calculation of concentration and volume for dosing correct?

Problem: Males do not produce mutant offspring.

\section{[Step 14]}

Solution: ENU is a powerful mutagen and mutations should be recovered. Dominant mutations should occur at a rate of one visible dominant mutation in every 100 offspring in the first generation of matings. Consider the following:

- If there are no visible mutations, the dose of ENU may be too low. Consider the strain background and check the calculation of ENU concentration/dose.

- The effective dose of ENU may be lower than calculated because of loss of activity. Use diluted ENU in a timely manner Do NOT store it in the freezer.

- A final possibility is that rotation matings were not used to recover mutagenized gametes (see Fig. 1). Remember that each male carries a different set of mutations; therefore, mutation recovery is a statistical sampling exercise and multiple males must be mated. 


\section{DISCUSSION}

ENU treatment of male mice is a simple and effective method for obtaining mutations in a forward genetic screen (Russell et al. 1979; Guenet 2005), and is now established as part of a mouse geneticist's toolkit. The method described here was designed to produce the highest mutation rates while avoiding toxicity (Russell et al. 1982). However, some knowledge of genetics is required in order for the protocol to be carried out effectively, so consult papers and textbooks for breeding schemes (Justice 1999). For example, many successful screens for dominant mutations have been conducted (Hrabe de Angelis and Balling 1998). Likewise, screens for recessive mutations using three generation pedigree breeding schemes or balancer chromosomes have been successfully carried out (Kasarskis et al. 1998; Herron et al. 2002; Kile et al. 2003). Banks of sperm and DNA samples from mutagenized males are useful for identifying point mutations in specific genes (Coghill et al. 2002) and, because of the advances in sequencing technology and mutation detection, molecular identification of point mutations is straightforward. Screens for modifying mutations are simple and effective in a small laboratory setting with limited amounts of mouse space, and are likely to be the most common use of forward genetics in the future (Carpinelli et al. 2004). Choosing the appropriate dose of ENU, according to experiment or strain background (Step 6), is very important (Justice et al. 2000). Although many strains, including $\mathrm{C} 57 \mathrm{BL} / 6$ ], can handle a high dose of ENU, an appropriate dose for FVB/N mice is only a single injection of $150 \mathrm{mg} / \mathrm{kg}$ body weight (Russell et al. 1979; Davis et al. 1999).

\section{REFERENCES}

Carpinelli, M.R., Hilton, D.J., Metcalf, D., Antonchuk, J.L., Hyl, C.D., Mifsud, S.L., Di Rago, L., Hilton, A.A., Willson, T.A., Roberts, A.W., et al. 2004. Suppressor screen in Mpl-/- mice: c-Myb mutation causes supraphysiological production of platelets in the absence of thrombopoietin signaling. Proc. Natl. Acad. Sci. 101: 65536558.

Coghill, E.L., Hugill, A., Parkinson, N., Davison, C., Glenister, P., Clements, S., Hunter, J., Cox, R.D., and Brown, S.D. 2002. A gene-driven approach to the identification of ENU mutants in the mouse. Nature Genet. 30: 255-256.

Davis, A.P., Woychik, R.P., and Justice, M.J. 1999. Effective chemical mutagenesis in $\mathrm{FVB} / \mathrm{N}$ mice requires low doses of ethylnitrosourea. Mamm. Genome 10: 308-310.

Guenet, J.-L. 2005. Chemical mutagenesis of the mouse genome: An overview. In Genetica: Mutagenesis of the mouse genome (eds. M. Justice and M. Bedell), pp. 9-24. Kluwer Academic Publications, Dordrecht, The Netherlands.

Herron, B.J., Lu, W., Rao, C., Liu, S., Peters, H., Bronson, R.T., Justice, M.J., McDonald, D., and Beier, D.R. 2002. Efficient generation and mapping of recessive developmental mutations using ENU mutagenesis. Nature Genet. 30: 185-189.

Hrabe de Angelis, M. and Balling, R. 1998. Large scale ENU screens in the mouse: Genetics meets genomics. Mutation Res.
400: $25-32$.

Justice, M.J. 1999. Mutagenesis of the mouse germline. In Mouse genetics and transgenics: A practical approach (eds. I. Jackson and C. Abbott), pp. 185-215. Oxford University Press, Oxford, UK.

Justice, M.J., Carpenter, D.A., Favor, J., Neuhauser-Klaus, A., Hrabe de Angelis, M., Soewarto, D., Moser, A., Cordes, S., Miller, D., Chapman, V., et al. 2000. Effects of ENU dosage on mouse strains. Mamm. Genome 11: 484-488.

Kasarskis, A., Manova, K., and Anderson, K.V. 1998. A phenotypebased screen for embryonic lethal mutations in the mouse. Proc. Nat. Acad. Sci. 95: 7485-7490.

Kile, B.T., Hentges, K.E., Clark, A.T., Nakamura, H., Salinger, A.P., Liu, B., Box, N., Stockton, D.W., Johnson, R.L., and Behringer, R.R., et al. 2003. Functional genetic analysis of mouse chromosome 11 . Nature 425: 81-86.

Russell, W.L., Kelly, E.M., Hunsicker, P.R., Bangham, J.W., Maddux, S.C., and Phipps, E.L. 1979. Specific-locus test shows ethylnitrosourea to be the most potent mutagen in the mouse. Proc. Natl. Acad. Sci. 76: 5818-5819.

Russell, W.L., Hunsicker, P.R., Raymer, G.D., Steele, M.H., Stelzner, K.F., and Thompson, H.M. 1982. Dose-response curve for ethylnitrosourea-induced specific-locus mutations in mouse spermatogonia. Proc. Natl. Acad. Sci. 79: 3589-3591. 


\section{Mouse Mutagenesis Using $\mathbf{N}$-Ethyl- $\mathbf{N}$-Nitrosourea (ENU)}

Andrew P. Salinger and Monica J. Justice

Cold Spring Harb Protoc; doi: 10.1101/pdb.prot4985

\begin{tabular}{|c|c|}
\hline $\begin{array}{l}\text { Email Alerting } \\
\text { Service }\end{array}$ & Receive free email alerts when new articles cite this article - click here. \\
\hline $\begin{array}{l}\text { Subject } \\
\text { Categories }\end{array}$ & $\begin{array}{l}\text { Browse articles on similar topics from Cold Spring Harbor Protocols. } \\
\text { Developmental Biology (728 articles) } \\
\text { Genetics, general ( } 374 \text { articles) } \\
\text { High-Throughput Analysis, general (155 articles) } \\
\text { Laboratory Organisms, general (923 articles) } \\
\text { Molecular Biology, general (1293 articles) } \\
\text { Mouse (437 articles) } \\
\text { Mutagenesis (57 articles) }\end{array}$ \\
\hline
\end{tabular}

